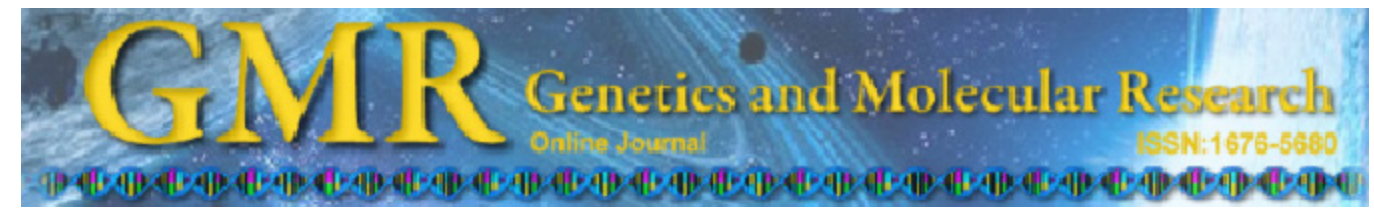

\title{
Genetic parameters for earnings in Quarter Horse
}

\author{
A.P.A. Silva ${ }^{1}$, R.A. Curi ${ }^{2}$, B. Langlois ${ }^{3}$ and J.A.II.V. Silva ${ }^{2}$ \\ ${ }^{1}$ Departamento de Zootecnia, Faculdade de Ciências Agrárias e Veterinárias, \\ Universidade Estadual Paulista, Jaboticabal, SP, Brasil \\ ${ }^{2}$ Departamento de Melhoramento e Nutrição Animal, \\ Faculdade de Medicina Veterinária e Zootecnia, \\ Universidade Estadual Paulista, Botucatu, SP, Brasil \\ ${ }^{3}$ Station de Génétique Quantitative et Appliquée, \\ Institut National de la Recherche Agronomique, \\ Jouy-en-Josas Cedex, France \\ Corresponding author: J.A.II.V. Silva \\ E-mail: jaugusto@fmvz.unesp.br
}

Genet. Mol. Res. 13 (3): 5840-5848 (2014)

Received February 6, 2014

Accepted May 15, 2014

Published August 1, 2014

DOI http://dx.doi.org/10.4238/2014.August.1.2

\begin{abstract}
In this study, we estimated the heritability $\left(\mathrm{h}^{2}\right)$ of earnings in the Quarter Horse in order to evaluate the inclusion of this trait in breeding programs. Records from 14,754 races of 2443 horses from 1978-2009 were provided by Sorocaba Hippodrome, São Paulo, Brazil. All ancestors of the registered horses were included in the pedigree file until the 4th generation. Log-transformed performance measures (LPM) were analyzed for animals aged 2, 3, and 4 years and during their entire career. The $\mathrm{h}^{2}$ estimates were obtained using a multi-trait model and Gibbs sampling that included the effects of sex, year of race, and animal in all analyses. Five analyses were performed: 1 in which LPM was divided by the number of prizes, 1 in which LPM was divided by the number of race starts, and 3 analyses that included the number of prizes, number of race starts, and both (LPM_cNPS) as covariates. Analysis was performed with and without inclusion of the maternal effect. Models were compared based on the deviance
\end{abstract}


information criterion and LPM_cNPS including maternal effects was found to be the best model. The $\mathrm{h}^{2}$ estimates and standard deviation obtained using model LPM_cNPS were $0.19 \pm 0.08,0.21 \pm 0.08,0.22$ \pm 0.09 , and $0.21 \pm 0.07$ for earnings at 2,3 , and 4 years of age and total career, respectively. Our analyses indicate that earnings are subject to selection and can be included in breeding programs to improve the racing performance of Quarter Horses.

Key words: Heritability; Prize money; Racehorses; Racing performance

\section{INTRODUCTION}

Quarter Horses are the 2nd most important racehorse breed in Brazil (ABQM, 2012). Studies evaluating the racing performance of Quarter Horses using race time, finish place, and speed index have been conducted in Brazil (Villela et al., 2002; Corrêa and da Mota, 2007), but there have been no studies examining genetic parameters including earnings (performance measures; PM), as a trait. PM has been extensively investigated in different horse breeds that participate in race competitions (Ekiz and Kocak, 2005; Svobodova et al., 2005; Langlois and Blouin, 2007; Gómez et al., 2010; Park et al., 2011), but not in Quarter Horses; understanding the genetic parameters related to this trait would improve the criteria typically used for evaluating racing performance.

In general, traits related to PM show low to moderate heritability $(0.02-0.30)$, indicating that identifying genetically superior horses is straightforward when based only on the animal performance. However, PM has not been examined in Quarter Horses, making it important to determine the magnitude and possible use of this trait in selection programs designed to improve racing performance.

The aim of this study was to evaluate genetic variability in PM, determine the relevance of including maternal effects in analysis models, and determine the potential for including this trait in genetic breeding programs of Quarter Horses.

\section{MATERIAL AND METHODS}

The data used in this study were obtained from Paulista Hippodrome in Sorocaba, São Paulo State, Brazil, and included 14,754 performance records of 2443 Quarter Horses collected in races from 1978-2009. The distances ranged from 275-503 m on dirt tracks with no handicap.

PM was analyzed when the animal was 2, 3, or 4 years old and throughout its career. For PM according to age, the annual prize money of the animal won at different ages was summed, whereas for total career earnings, the money won in all races throughout the animal life was summed.

Two important observations should be noted: a) because the prize money was earned in different currencies, the values were converted to US dollars by using the average conversion rate of the month within the year of the race and based on the prevailing currency during the period (indexed to dollar to eliminate the effect of inflation in Brazil), and b) because PM did not show a normal distribution, logarithmic transformation was applied (Snedecor and Co- 
chran, 1967) to produce a frequency distribution closest to normality as verified by the Shapiro and Wilk test by using SAS (Shapiro and Wilk, 1965).

After logarithmic transformation, log PM (LPM) was evaluated through 5 analyses: 1 in which LPM was divided by the number of prizes (LPM/NP), 1 in which LPM was divided by the number of race starts (LPM/NS), and 3 analyses that included the number of prizes (LPM_cNP), number of race starts (LPM_cNS), and both (LPM_cNPS) as covariates (linear and quadratic) affecting the trait. The relationship between PM and the covariates studied or between the latter qualities was not linear. Analysis was performed using multi-trait models that included all PM traits at 2, 3, and 4 years of age and total career earnings, in which the traits were separated according to the 5 analyses described above.

The model included the effect of the animal, as well as the effects of sex and year of participation in the races. The linear covariate of age at racing was added only for total career earnings. In addition, the analyses were performed with or without including the maternal effect. Inclusion of the maternal effect in the models was motivated by the studies of Langlois and Blouin (2004) and Langlois and Vrijenhoek (2004), who suggested this effect to be important as it helps with interpreting the difference between paternal and maternal variance components. This difference results from common environmental factors for the offspring of the same mare; in most cases, an owner only has 1 or a few mares, and thus the maternal effect (sensu stricto) is confounded by the influence of the breeder (Langlois and Blouin, 2004).

The relationship matrix included 4150 animals and ancestors up to the 4th generation. For statistical analysis, genetic (co)variance components of the traits were estimated by Bayesian inference under a complete multi-trait animal model. Analyses were performed using the GIBBS2F90 program (Misztal, 2002) and the post-Gibbs sampling results were analyzed using the POSTGIBBSF90 program (Misztal, 2002). Single chains of 500,000 cycles were run, with a burn-in period of 20,000 cycles determined after demonstration of the stationary distribution of each chain by visual inspection (Kass et al., 1998). Values were stored at intervals of 20 iterations, for a total of 24,000 samples. These samples were used to compute posterior means, standard deviations, and confidence intervals. The initial values of the (co)variance components were the same for all analyses and were determined by previous restricted maximum likelihood analysis using linear models (Kass et al., 1998).

Post-Gibbs analysis provided information on the convergence of the chain and, among other values, presents the effective sample size, the mean that estimates the number of independent samples with information equivalent to that present in the dependent sample (Sorensen et al., 1995).

The description of the data used in the analyses is shown in Tables 1 and 2.

Table 1. Description of the traits earnings (PM) at 2, 3, or 4 years of age and total career of Quarter Horse
racehorses.
\begin{tabular}{lcccccc}
\hline Trait & Animals (N) & Males (N) & Sires (N) & Dams (N) & Mean number of prizes & Mean number of race starts \\
\hline PM at 2 years & 351 & 167 & 148 & 294 & 1.93 & 4.36 \\
PM at 3 years & 1941 & 826 & 283 & 1093 & 2.17 & 4.73 \\
PM at 4 years & 498 & 215 & 163 & 404 & 1.98 & 4.00 \\
Total career earnings & 2443 & 1052 & 362 & 1328 & 2.54 & 6.04 \\
\hline
\end{tabular}


Table 2. Mean and standard deviation of earnings at 2, 3, or 4 years and total career of Quarter Horse racehorses.

\begin{tabular}{lccc}
\hline & LPM & LPM/NP & LPM/NS \\
\hline 2 years & $6.41 \pm 1.86$ & $5.95 \pm 1.72$ & $5.13 \pm 1.78$ \\
3 years & $6.72 \pm 2.00$ & $6.13 \pm 1.78$ & $5.34 \pm 1.87$ \\
4 years & $6.58 \pm 1.71$ & $6.07 \pm 1.54$ & $5.37 \pm 1.56$ \\
Total career & $6.79 \pm 1.98$ & $6.11 \pm 1.72$ & $5.22 \pm 1.81$ \\
\hline
\end{tabular}

$\mathrm{LPM}=$ logarithmic transformation of earnings; LPM/NP and LPM/NS = earnings divided by the number of prizes and the number of race starts, respectively.

Deviance information criterion (DIC) was used for model comparison to determine the best-fitting model. With $\theta$ corresponding to the parameters of the model, DIC was calculated as:

$$
D I C=D(\theta)+P_{D(\theta)}
$$

where $\bar{D}(\theta)$ was the posterior mean of the deviation, which is $-2 \log \mathrm{p}(\mathrm{y} \mid \theta)$. The effective number of parameters $P_{D(\bar{\theta})}$ was determined by $P_{D(\bar{\theta})}=\bar{D}(\theta)-D \overline{(\theta)}$, where $\bar{\theta}$ was the posterior mean of $\theta$. Low DIC values indicate a better fit, with penalization of complex models based on the effective number of parameters (Spiegelhalter et al., 2002). According to these authors, subtraction of the DIC from different models resulting in a value of 7 indicates an important difference in model fit.

To analyze genetic trends, regression of predicted breeding values was performed based on the means weighted by the number of observations within the respective year of birth. Only animals born from 1979-2007 were considered. The PROC REG procedure of the SAS software (2000) was used.

Rank correlations (Spearman) based on breeding values of stallions with more than 10 offspring and the top $10 \%$ were obtained using the PROC CORR procedure of the SAS program (2000).

\section{RESULTS AND DISCUSSION}

Model comparison based on the parameters shown in Table 3 revealed lower DIC values for models that included the maternal effect, indicating a better fit. LPM/NP and LPM/ NS include a ratio, i.e., they consist of 2 variables, which according to MacNeil (2005), complicate selection by shifting the emphasis to the component traits. Additionally, predicting genetic gain when the selection criterion is a ratio is extremely complex.

When comparing other models that included the maternal effect and covariates (LPM_cNP, LPM_cNS and LPM_cNPS), LPM_cNPS was considered to be the best model for estimating PM since; in addition to presenting the lowest DIC value, the traits also showed lower estimates of residual variance and higher heritability values. Therefore, the results obtained using this model will be discussed below, as well as the analysis of genetic trends and rank correlations.

For all models, the minimum effective size obtained by post-Gibbs analysis for all components was 15 samples, demonstrating that the number of cycles used $(500,000)$ 
was adequate for convergence of the chain. According to Misztal (2002), components with an effective size larger than 10 are considered to be converged. For all parameters, the absolute values of Geweke's Z statistics (Geweke, 1992) were below 1.96 and the dependence factor of Raftery and Lewis (1992) were below 5.0, indicating that convergence was reached.

\begin{tabular}{|c|c|c|c|c|}
\hline Model & Maternal effect & DEV & $\mathrm{Pd}$ & DIC \\
\hline \multirow[t]{2}{*}{ LPM/NP } & Yes & $-16,818.611$ & -7933.398 & $-24,752.009$ \\
\hline & No & -7355.348 & -3749.168 & $-11,104.516$ \\
\hline \multirow[t]{2}{*}{ LPM/NS } & Yes & $-13,203.764$ & -8183.129 & $-21,386.893$ \\
\hline & No & -763.974 & -1413.870 & -2177.844 \\
\hline \multirow[t]{2}{*}{ LPM_cNP } & Yes & -107.545 & 610.216 & 502.670 \\
\hline & No & 1921.997 & 475.409 & 2397.406 \\
\hline \multirow[t]{2}{*}{ LPM_cNS } & Yes & -4876.818 & -3086.650 & -7963.468 \\
\hline & No & 1749.633 & 457.845 & 2207.477 \\
\hline \multirow[t]{2}{*}{ LPM_cNPS } & Yes & -7383.231 & -6671.286 & $-14,054.517$ \\
\hline & No & 3189.559 & 477.757 & 3667.316 \\
\hline
\end{tabular}

LPM/NP, LPM/NS, LPM_cNP, LPM_cNS, and LPM_cNPS = logarithmic transformation of earnings divided by the number of prizes, divided by the number of race starts, including the covariate number of prizes, including the covariate number of race starts, and including both covariates, respectively.

Table 4 shows the posterior means of residual variance and heritability for traits obtained using the models proposed. Higher residual variances for LPM at different ages and total career were obtained using the models that did not include the maternal effect, suggesting that when this effect is not included in the model, its value is added to the residual variance, with a smaller difference between models when the trait is measured at an older age.

Table 4. Heritability and residual variance obtained with models with and without maternal effect used to estimate earnings at 2,3, or 4 years of age and total career of Quarter Horse racehorses.

\begin{tabular}{|c|c|c|c|c|c|c|c|c|c|}
\hline \multirow[t]{2}{*}{ Model } & \multirow[t]{2}{*}{ Maternal effect } & \multicolumn{2}{|c|}{2 years } & \multicolumn{2}{|c|}{3 years } & \multicolumn{2}{|c|}{4 years } & \multicolumn{2}{|c|}{ Total career } \\
\hline & & $\sigma_{r}^{2}$ & $\mathrm{~h}^{2}$ & $\sigma_{r}^{2}$ & $\mathrm{~h}^{2}$ & $\sigma_{r}^{2}$ & $\mathrm{~h}^{2}$ & $\sigma_{r}^{2}$ & $\mathrm{~h}^{2}$ \\
\hline \multirow[t]{2}{*}{ LPM/NP } & Yes & 1.44 & 0.16 & 1.45 & 0.19 & 1.05 & 0.22 & 1.37 & 0.19 \\
\hline & No & 1.43 & 0.19 & 1.44 & 0.20 & 1.10 & 0.23 & 1.35 & 0.20 \\
\hline \multirow[t]{2}{*}{ LPM/NS } & Yes & 1.57 & 0.21 & 1.69 & 0.19 & 1.13 & 0.25 & 1.60 & 0.20 \\
\hline & No & 1.60 & 0.23 & 1.72 & 0.18 & 1.22 & 0.24 & 1.62 & 0.19 \\
\hline \multirow[t]{2}{*}{ LPM_cNP } & Yes & 1.45 & 0.19 & 1.47 & 0.21 & 1.04 & 0.21 & 1.46 & 0.21 \\
\hline & No & 1.48 & 0.19 & 1.51 & 0.20 & 1.15 & 0.19 & 1.48 & 0.19 \\
\hline \multirow[t]{2}{*}{ LPM_cNS } & Yes & 1.63 & 0.21 & 1.73 & 0.21 & 1.14 & 0.28 & 1.67 & 0.21 \\
\hline & No & 1.68 & 0.20 & 1.75 & 0.19 & 1.28 & 0.25 & 1.69 & 0.20 \\
\hline \multirow{2}{*}{ LPM_cNPS } & Yes & 1.43 & 0.19 & 1.46 & 0.21 & 1.05 & 0.22 & 1.45 & 0.21 \\
\hline & No & 1.47 & 0.19 & 1.49 & 0.21 & 1.17 & 0.19 & 1.47 & 0.20 \\
\hline
\end{tabular}

For abbreviations, see legend to Table 3.

Residual variance for LPM at 3 years was higher for all models and between traits, indicating a greater environmental effect at this age and an influence on LPM. Additionally, a larger number of animals are culled at this age because of unsatisfactory results for breeders. The heritability for the LPM traits studied was similar and of medium magnitude (Table 4), indicating that selecting for these traits should result in moderate genetic changes. Similar es- 
timates have been reported by Langlois et al. (1996) for LPM at 2 years $(0.22-0.28)$ and lower estimates by Langlois et al. (1975) for LPM at 2 years $(0.02-0.06)$ and by Gallizi-Vecchiotti and Pazzaglia (1976) for PM at 2 and 3 years (0.04 and 0.12, respectively). For Thoroughbred horses, Langlois (1975) and Ekiz et al. (2005) obtained moderate to high heritability values for earnings $(0.40-0.56 ; 0.34)$. Higher heritability values were estimated for LPM at 4 years for the different statistical models.

When the maternal effect was not included in the models, alterations in additive genetic and residual variances were observed, but without respect to the trends or proportions at different ages or for total career earnings (Table 4). In general, residual variances for LPM were higher than the estimates obtained for the same trait when maternal effects were considered, except for residual variances at 2 and 3 years of age and total career earnings obtained using the LPM/NP model, which were slightly lower.

Heritability values were directly related to residual variances, demonstrating that traits with lower residual variances have higher heritability when compared to the same traits for which maternal effects were taken into account. The opposite was also observed (Table 4). In general, the heritability values for LPM at different ages and for total career earnings were similar when the number of race starts or prizes was included as a covariate in the model. These heritability values were of moderate magnitude, indicating a reasonable relationship between breeding values and the performance of horses in terms of prize money won.

Decreased residual variance and higher heritability were observed for all ages and total career when maternal effects and the covariate number of race starts and number of prizes were included in the models (Table 4); however, the heritability estimated using the LPM_cNPS model was identical at 2 and 3 years of age and at 2 years with the LPM_cNP model, regardless of whether the maternal effect was included.

Averages of the estimates of maternal heritability values at 2,3, and 4 years of age and career for all of the models studied were identical to the values found in the analysis considered to show the best adjustment (LPM cNPS). Therefore, the estimates of maternal heritability at 2,3 , and 4 years of age and career were, respectively, 0.017, 0.005, 0.083, and 0.003 , which when added to the direct heritability (Table 4), resulted total heritability values of $0.21,0.22,0.27$, and 0.21 . These results indicate the importance of including the maternal effect in the evaluations.

With respect to the covariate number of race starts, the heritability values obtained were higher than those reported by Pieramati et al. (2010) for Italian Trotter horses, which was $0.19 \pm 0.006$. Similar values were obtained when considering the covariate number of prizes at different ages, indicating a trend towards a balanced distribution of prizes throughout the career of these animals. Heritability for LPM at 4 years of age was higher than that reported by Ojala (1987) for Finnish horses of the same age, which was $0.09 \pm 0.03$, whereas the same value as obtained in the present study was reported for Standardbreds (0.21). Similar heritability values were observed for LPM of animals at 2 and 3 years of age when the covariate total number of race starts was included. In addition, the heritability for LPM at 4 years of age was higher than that observed at the other 2 ages studied.

Genetic correlations between LPM at different ages and total career obtained using the LPM_cNPS model are shown in Table 5. The correlations were positive and of high magnitude, indicating that selection for some of these traits will result in favorable genetic changes for the other traits. LPM at 2, 3, or 4 years has a genetic basis that is similar to that of total 
career of the animal, although directly selecting for this trait would be more efficient than indirect selection based on any LPM at the other ages studied.

Table 5. Genetic correlations between earnings (LPM) at 2, 3, or 4 years of age and total career of Quarter
Horse racehorses obtained with the model including maternal effects and the number of prizes and race starts
as covariates.
\begin{tabular}{lccc} 
& & \\
\hline LPM & 2 years & 3 years & 4 years \\
\hline 3 years & 0.95 & 0.81 & 0.84 \\
Tyears & 0.85 & 0.99 & \\
Total career & 0.96 & &
\end{tabular}

The LPM_cNPS model was used to estimate the mean, standard deviation, and range of predicted breeding values for all animals of the pedigree and only for stallions with more than 10 offspring (Table 6). Breeding values of stallions presented higher standard deviations and similar minimum values when compared to the entire population, demonstrating that lower limits are representative of stallions with more than 10 offspring, which is concerning. The values reflect genetic variability in the traits; the difference in breeding values between the animals analyzed indicates a difference in profitability at the ages studied. For example, if between the highest (1.38) and lowest (-1.00) predicted breeding value of stallions for profitability at 3 years of age (LPM3) is 2.38, the offspring produced would have an annual gain of 1.19 (corresponding to 14.49 dollars when transformed from the logarithmic function) if the stallions are mated with females that present the same breeding value.

Table 6. Number of observations (N), mean, standard deviation (SD), and minimum and maximum breeding values for earnings at 2, 3, or 4 years of age and total career of Quarter Horse racehorses obtained for the whole dataset (Total) and for stallions with more than 10 offspring.

\begin{tabular}{llrcccc}
\hline Trait & & $\mathrm{N}$ & Mean & SD & Minimum & Maximum \\
\hline LPM2 & Stallions & 67 & 0.14 & 0.42 & -0.86 & 1.25 \\
& Total & 4150 & 0.15 & 0.34 & -0.86 & 1.46 \\
LPM3 & Stallions & 67 & 0.17 & 0.46 & -1.00 & 1.38 \\
& Total & 4150 & 0.17 & 0.38 & -1.00 & 1.61 \\
LPM4 & Stallions & 67 & 0.12 & 0.36 & -0.71 & 1.06 \\
& Total & 4150 & 0.12 & 0.28 & -0.72 & 1.18 \\
LPMC & Stallions & 67 & 0.16 & 0.46 & -0.93 & 1.57 \\
& Total & 4150 & 0.17 & 0.37 & -0.93 & \\
\hline
\end{tabular}

LPM2, LPM3, LPM4, and LPMC = logarithmic transformation of earnings at 2, 3, and 4 years of age and total career of the animal, respectively.

The rank correlations considering 67 sires with more than 10 offspring obtained using the LPM_cNPS model (including maternal effects) ranged from 0.94 (between 3 and 4 years) to 0.99 (between 2 and 3 years and total career), with a mean of 0.97 , indicating that the stallions chosen are essentially the same at different ages. Slightly lower rank correlations $(0.88)$ were observed for the group of the top $10 \%$ sires (7) with more than 10 offspring, a group that is expected to be more intensively used (Table 7). 
Table 7. Rank correlations between earnings (LPM) at 2, 3, or 4 years of age and total career of Quarter Horse racehorses obtained for stallions with more than 10 offspring (above the diagonal) and the top $10 \%$ (below the diagonal).

\begin{tabular}{lcccc}
\hline PM & 2 years & 3 years & 4 years & Total career \\
\hline 2 years & & $0.98 \pm 0.02$ & $0.97 \pm 0.04$ & $0.99 \pm 0.02$ \\
4 years & $0.93 \pm 0.02$ & & $0.94 \pm 0.03$ & $0.99 \pm 0.01$ \\
4 years & $1.00 \pm 0.04$ & $0.93 \pm 0.03$ & $0.79 \pm 0.02$ & $0.96 \pm 0.05$ \\
Total career & $0.79 \pm 0.03$ & $0.82 \pm 0.03$ & \\
\hline
\end{tabular}

Genetic trends for LPM at different ages and total career obtained with LPM_cNPS are illustrated in Figure 1. Cumulative prize money earned during the career of the animal showed a higher annual gain, whereas a slightly lower trend was observed at 4 years, with a difference of 0.003 units or 0.007 dollars per year.

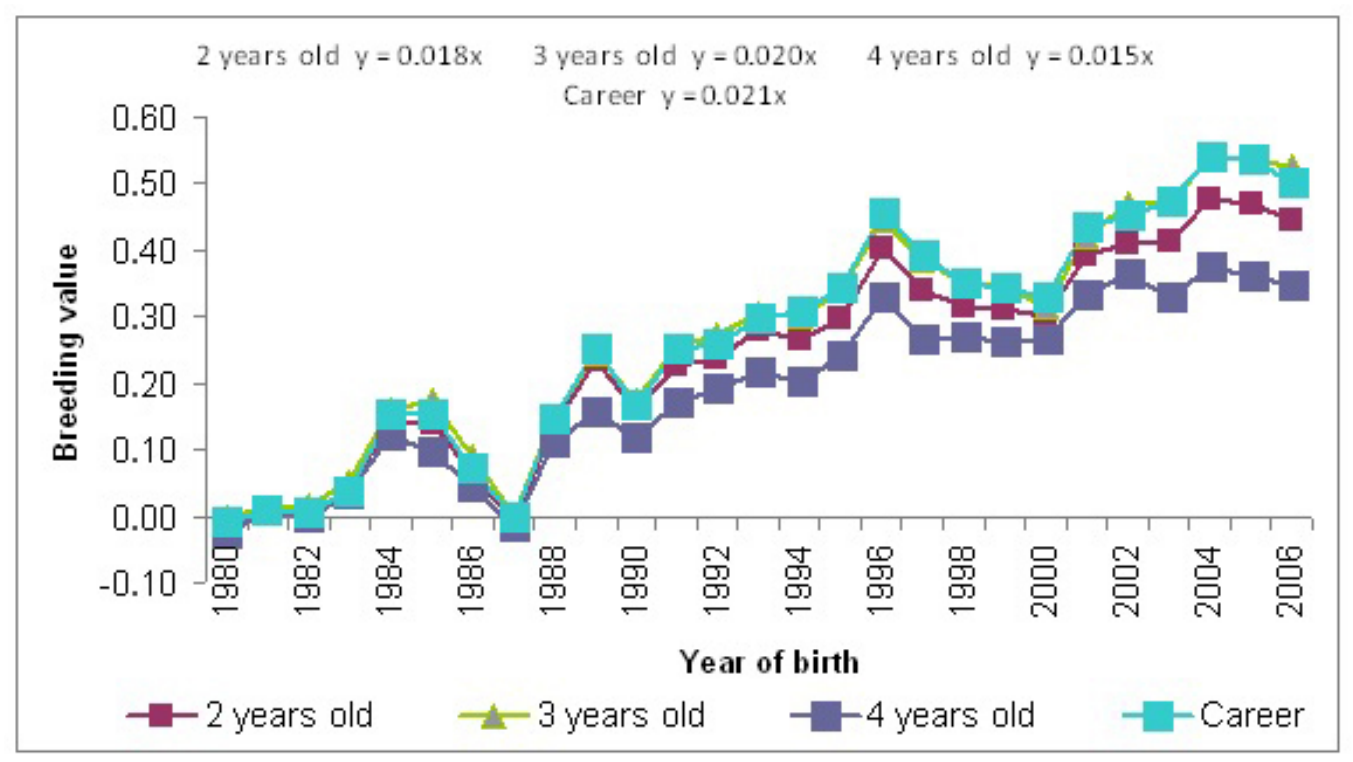

Figure 1. Genetic trends in earnings at 2, 3, and 4 years and total career of Quarter Horse racehorses obtained using the LPM_cNPS model.

\section{CONCLUSIONS}

Maternal effects were found to be relevant for evaluating traits related to earnings and should be included in analysis models. In addition, the heritability values suggested that this trait should be included in genetic breeding programs of Quarter Horses in Brazil.

\section{ACKNOWLEDGMENTS}

The authors thank Prof. Marcílio Dias Silveira da Mota, who left us prematurely, for the enormous contribution to this manuscript; we honor his memory. 


\section{REFERENCES}

ABQM (2012). Associação Brasileira de Criadores de Cavalo Quarto de Milha. Available at [http://www.abqm.com.br/]. Accessed April 20, 2012.

Correa MJ and da Mota MD (2007). Genetic evaluation of performance traits in Brazilian Quarter Horse. J. Appl. Genet. 48: $145-151$

Ekiz B and Kocak O (2005). Phenotypic and genetic parameter estimates for racing traits of Arabian horses in Turkey. $J$. Anim. Breed Genet. 122: 349-356.

Ekiz B, Kocak O and Yilmaz A (2005). Phenotypic and genetic parameter estimates for racing traits of Thoroughbred horses in Turkey. Arch. Tiez. Dummerstorf. 48: 121-129.

Gallizi-Vecchiotti AG and Pazzaglia G (1976). Ereditabilità dell'attitudine alla corsa del puro sangue inglese studiata su corse piane italiane. Atti Soc. Ital. Sci. Vet. 30: 490-492.

Geweke J (1992). Evaluating the Accuracy of Sampling-Based Approaches to the Calculation of the Posterior Moments. In: Bayesian Statistics (Bernardo JM, Berger JO, Dawid AP and Smith AFM, eds.). 4th edn. Oxford University Press, Oxford, 490-492.

Gómez MD, Menendez-Buxadera A, Valera M and Molina A (2010). Estimation of genetic parameters for racing speed at different distances in young and adult Spanish Trotter horses using the random regression model. J. Anim. Breed Genet. 127: 385-394.

Kass RE, Carlin BP, Gelman A and Neal RM (1998). Markov Chain Monte Carlo in practice: A roundtable discussion. Am. Statist. 52: 93-100.

Langlois B and Blouin C (2004). Practical efficiency of breeding value estimations based on annual earnings of horses for jumping, trotting and galloping races in France. Livest. Prod. Sci. 87: 99-107.

Langlois B and Vrijenhoek T (2004). Qualification status and estimation of breeding value in French trotters. Livest. Prod. 89: 187-194.

Langlois B and Blouin C (2007). Annual career or single race records for breeding value estimation in racehorses. Livest. Sci. 107: 132-141.

Langlois B, Poirel D, Tastu D and Rose J (1975). Analyse statistique et génétique des gains des pur sang anglais de trois ans dans les courses plates françaises. Ann. Genet. Sel. Anim. 7: 387-408.

Langlois B, Blouin CA and Tavernier A (1996). Nouveaux résultats d'estimation de l'héritabilité des gains en course des pur-sang en France. Genet. Sel. Evol. 28: 275-283.

MacNeil MD (2005). Genetic evaluation of the ratio of calf weaning weight to cow weight. J. Anim. Sci. 83: 794-802.

Misztal I (2002). GIBBS2F90 Manual. Available at [http://nce.ads.uga.edu/ ignacy/numpub/blupf90/docs/blupf90.pdf]. Accessed September 10, 2010.

Ojala MJ (1987). Heritabilities of annually summarized race records in trotters. J. Anim. Sci. Finland. 64: 117-125.

Park JE, Lee JR, Oh S and Lee JW (2011). Principal components analysis applied to genetic evaluation of racing performance of Thoroughbred race horses in Korea. Livest. Sci. 135: 293-299.

Pieramati C, Fusaioli L, Scacco L, Buttazzoni L, et al. (2010). On the use of elo rating on harness racing results in the genetic evaluation of trotter. Ital. J. Anim. Sci. 6: 189-191.

Raftery AL and Lewis S (1992). How Many Iterations in the Gibbs Sampler? In: Bayesian Statistics. 4th edn. (Bernardo JM, Berger JO, Dawid AP and Smith AFM, eds.). Oxford University Press, Oxford, 763-774.

SAS (2000). User's Guide: Basics and Statistics. SAS Inst. Inc., Cary.

Shapiro SS and Wilk MB (1965). An analysis of variance test for normality (complete samples). Biometrika 52: 591-611. Snedecor GW and Cochran WG (1967). Statistical Methods. 6th edn. The Lowa State University Press, Ames.

Sorensen DA, Andersen S, Gianola D and Korsgaard I (1995). Bayesian inference in threshold models using Gibbs sampling. Genet. Sel. Evol. 27: 229-249.

Spiegelhalter DJ, Best NG, Carlin BP and Van Der Linde A (2002). Bayesian measures of model complexity and fit. $J . R$. Stat. Soc. Series B Stat. Methodol. 64: 583-639.

Svobodova S, Blouin C and Langlois B (2005). Estimation of genetic parameters of Thoroughbred racing performance in the Czech Republic. Anim. Res. 54: 499-509.

Villela LCV, Mota MDS and Oliveira HN (2002). Genetic parameters of racing performance traits of quarter horses in Brazil. J. Anim. Breed. Genet. 119: 229-234. 